\title{
Computational Models for Reduction of Quarry Waste for Breakwater Construction Projects
}

\author{
Venkateswara Rao Surati ${ }^{1}$, Koshy Varghese ${ }^{2}$ and K. Senthilnathan ${ }^{3}$ \\ ${ }^{1}$ M.Tech Student, Construction Technology \& Management, Indian Institute of Technology Madras \\ ${ }^{2}$ Professor, Department of Civil Engineering, Indian Institute of Technology Madras \\ ${ }_{3}^{3}$ Head, Engineering Technology (Infrastructure), Larsen and Toubro Limited, ECC Division, Chennai
}

\begin{abstract}
Construction of Breakwater requires large volumes of appropriately graded rock. Geological characteristics and blasting practices at the quarry determine the gradation of the quarried rock. If the gradation of quarried rock does not meet design requirements, there is wastage of quarried rock or additional cost to reprocess it to meet requirements. This work utilizes mathematical models to forecast the gradation of rock from primary blasting. These models are programmed in the form of a spreadsheet to be used for decision support. By varying the blasting parameters the best fit between requirements and quarry yield can be found. In addition, a genetic algorithm based optimization model to determine the optimal values is also developed and illustrated with an example.
\end{abstract}

Keywords: Breakwater rock demand, Quarry yield, Blasting parameters, Spreadsheet, Genetic Algorithms.

\section{Introduction}

Breakwater construction involves quarrying, transportation and placing large volumes of appropriately graded rock. The large volumes of rock required and the gradation specified usually necessitates dedicated quarries for the project. Ideally, based on the geology of the quarry and blasting methods, the blasting pattern can be designed to ensure that the rock yield from primary blasting is close to the specified gradation. However, common practice is to produce large size rocks through primary blasting and then break these down to required specifications using secondary blasting. (Carlos, et. al. 1995) This process adds to the cost of the operation and results in considerable wastage of materials.

One of the key reasons for the current practice is that there are no standardized methods and decision support tools available to assist in forecasting the quarry yield for quarry characteristics and alternate blasting patterns (Clarke et. al. 2005). The objective of this work is to propose a decision support methodology based on available models and develop a tool to implement the methodology. The work utilizes the Rosin Rammler model (Vrijling et. al. 1990) to forecast quarry yield. A spreadsheet is used to encode the workflow of the methodology. In addition, the optimization features of the spreadsheet are used to automate the selection of the blasting parameters to minimize excess material. The utility of the tool is illustrated using an example.

\section{Proposed Methodology}

Figure 1 shows an overview of the proposed methodology. The design specifications for a particular section of the breakwater are considered as the initial input to the process. It is assumed that the design of the breakwater is frozen and the blasting parameters can be varied to ensure quarry yield obtained matches with the given design requirements.

The design requirement is based on the coastal parameters and properties of rock available in the quarry. The requirements will specify the various sections of the break water and the required gradation of rock for each section. Figure 2 shows typical sections of a breakwater and Figure 3 shows the rock demand requirements for the sections. The yield of the quarry must match with the demand to ensure adequate supply of materials with minimum wastage. 
As shown in Figure 1, the yield of the quarry is based on geological characteristics (Rock Intact properties) of the quarry and blasting pattern utilized. Detailed mathematical models have been formulated to estimate the quarry yield.

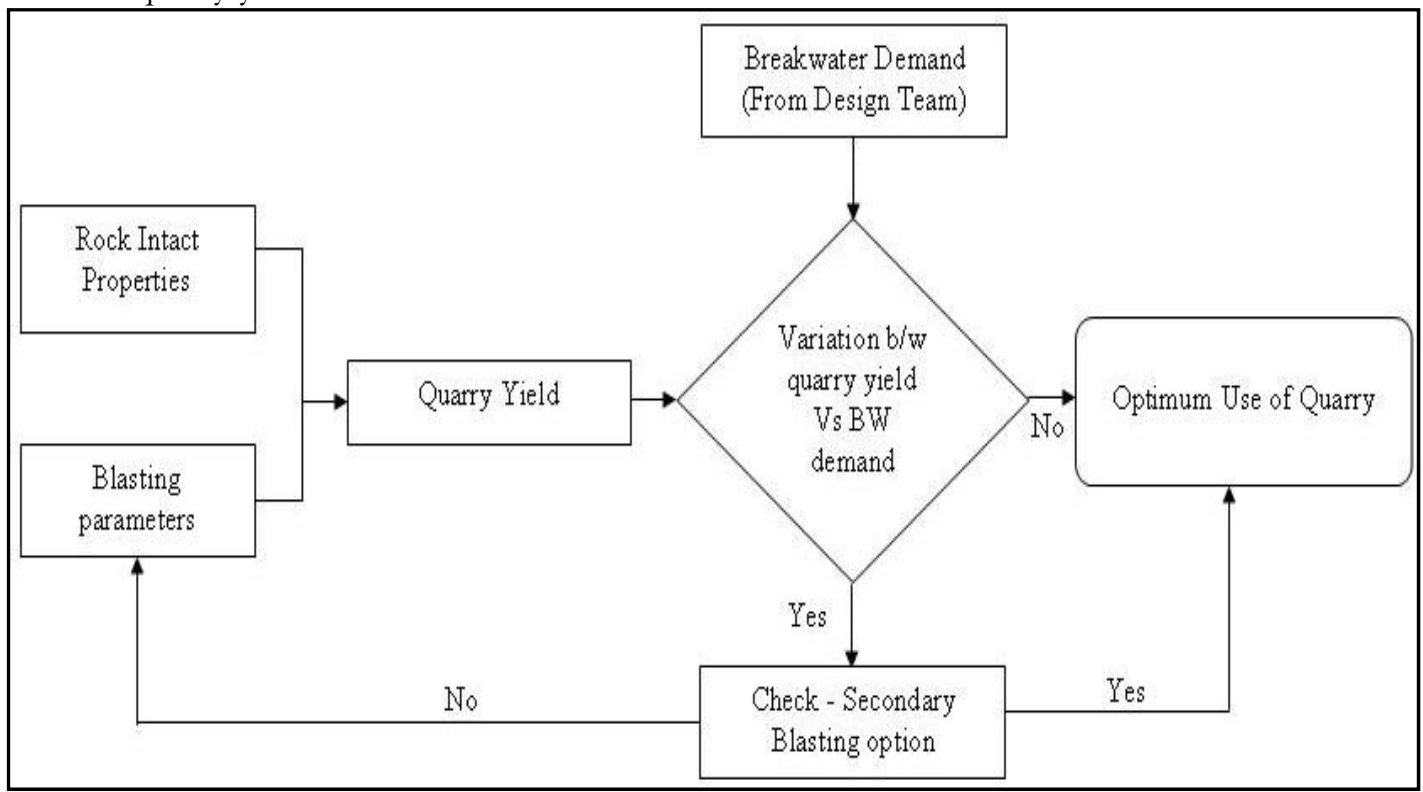

Figure 1 Proposed Methodologv - Optimal use of Quarry

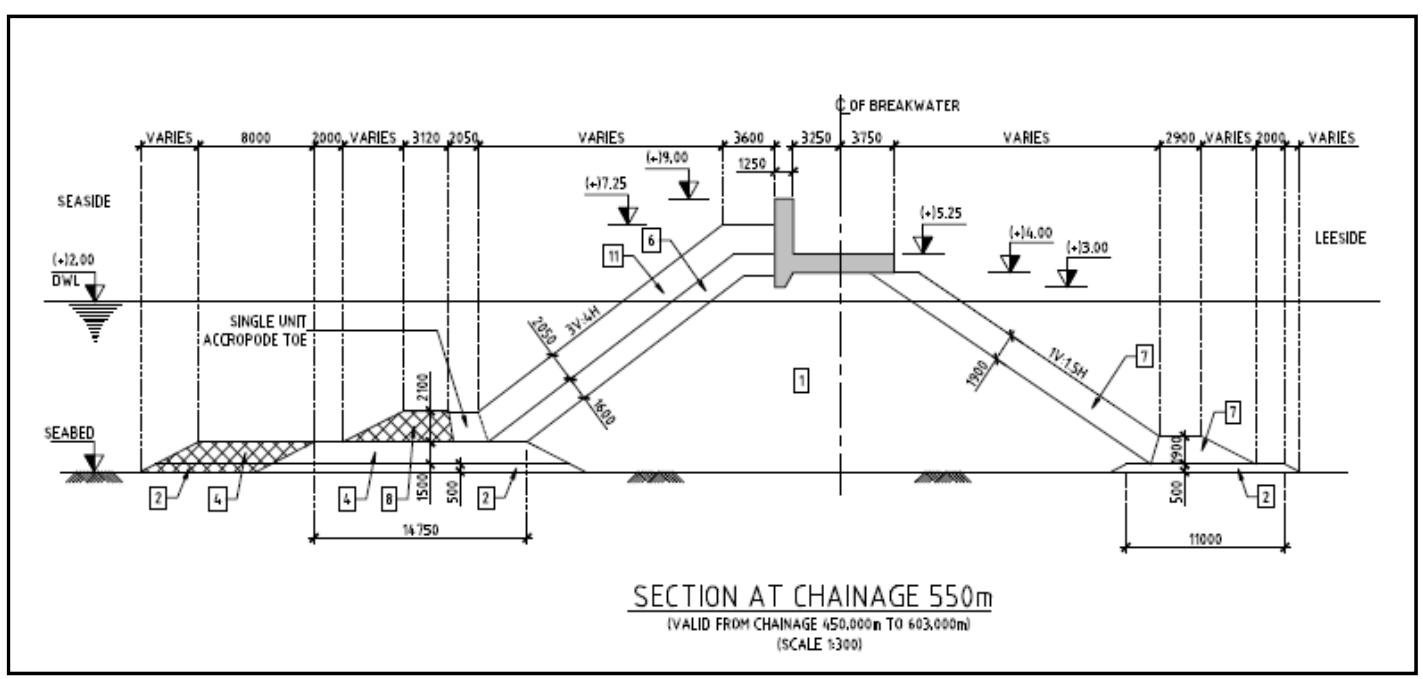

Figure 2 Typical Section of Rubble Mound Breakwater

\section{Model for Quarry Yield:}

The quarry yield for this work is calculated using the equation specified by equation (1): (Latham, et. al. 2006a) (Latham, et. al. 2006b)

$$
\mathrm{Y}=1-\exp \left\{-0.693\left(\mathrm{D}_{\mathrm{y}} / \mathrm{D}_{\mathrm{b} 50}\right)^{\mathrm{nRRD}}\right\}
$$

Where:

$D_{y}$ - Specific particle size

$D_{b 50}-50 \%$ passing sieve size in the blast pile

$n_{\mathrm{RRD}}$ - Rosin-Rammler uniformity index for sizes

$\mathrm{D}_{\mathrm{b} 50}$ is given by Kuznetsov equation; this suggests that average size is controlled by specific charge. 


$$
D_{b 50}=0.01 \cdot A \cdot(V / Q)^{0.8} \cdot Q^{0.167} \cdot(E / 115)^{0.633}
$$

Where:

$$
\begin{aligned}
& A=\text { rock factor }- \text { calculated by equation }(3) \\
& Q=\text { charge concentration per blast bole }(\mathrm{kg}) \\
& V=\text { volume of rock broken per blast hole }\left(\mathrm{m}^{3}\right) \\
& E=\text { relative weight strength of explosive }(A N F O=100, T N T=115) ;
\end{aligned}
$$

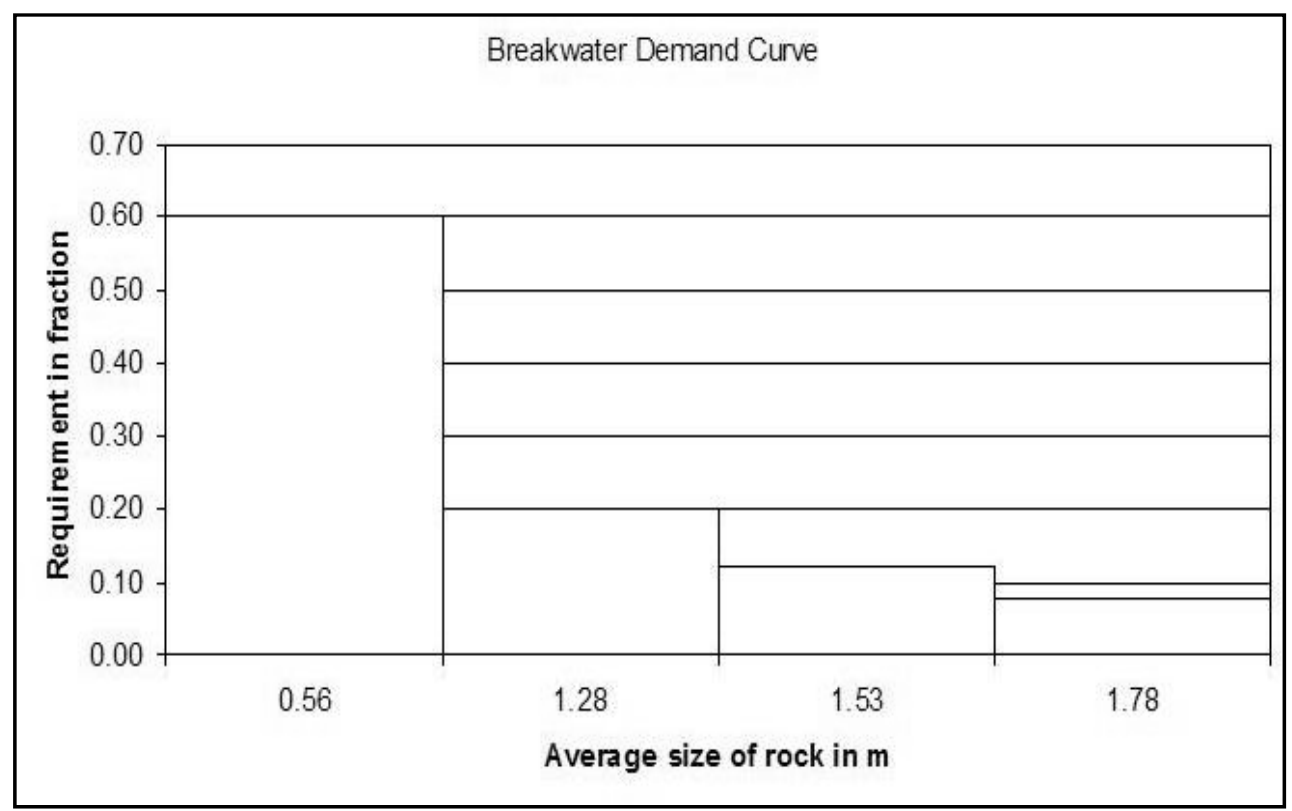

Figure 3 Demand Chart - Breakwater

Rock factor A:

$$
A=0.06(R M D+J F+R D I+H F)
$$

Where

RMD (Rock mass description): 10 if powdery or friable, $=J F$ if vertically jointed, 50 if massive rock.

JF (Joint Factor): Joint Plane Spacing term (JPS) + Joint Plane Angle term (JPA)

$J P S=10$ if average Principal Mean Spacing $(P M S)<0.1 \mathrm{~m} ; 20$ if $0.1<$ average PMS $<$ to $1 \mathrm{~m}$;

50 if average $P M S>1 \mathrm{~m}$.

$J P A=20$ if dipping out of face, 30 if striking perpendicular to face, 40 if dipping into face

$\mathrm{RDI}=$ Rock Density Influence $=0.025 \mathrm{er}\left(\mathrm{kg} / \mathrm{m}^{3}\right)-50$

$H F=$ Hardness factor $=E / 3$ if $E<50$, or UCS $/ 5$ if $>50$, depending on uniaxial compressive strength UCS (MPa) or Young's Modulus E (GPa).

er $=$ Rock Density

$\mathrm{n}_{\mathrm{RRD}}$ in equation (1) is determined using Cunningham's uniformity index formula

$$
\begin{aligned}
\mathrm{n}_{\mathrm{RRD}}= & \mathrm{X}(2.2-14 \mathrm{~B} / \mathrm{d})\{0.5(1+\mathrm{S} / \mathrm{B})\}^{0.5}(1-\mathrm{W} / \mathrm{B}) \\
& ((|(\mathrm{BCL}-\mathrm{CCL})| / \mathrm{L})+0.1)^{0.1} \mathrm{~L} / \mathrm{H}
\end{aligned}
$$

Where 


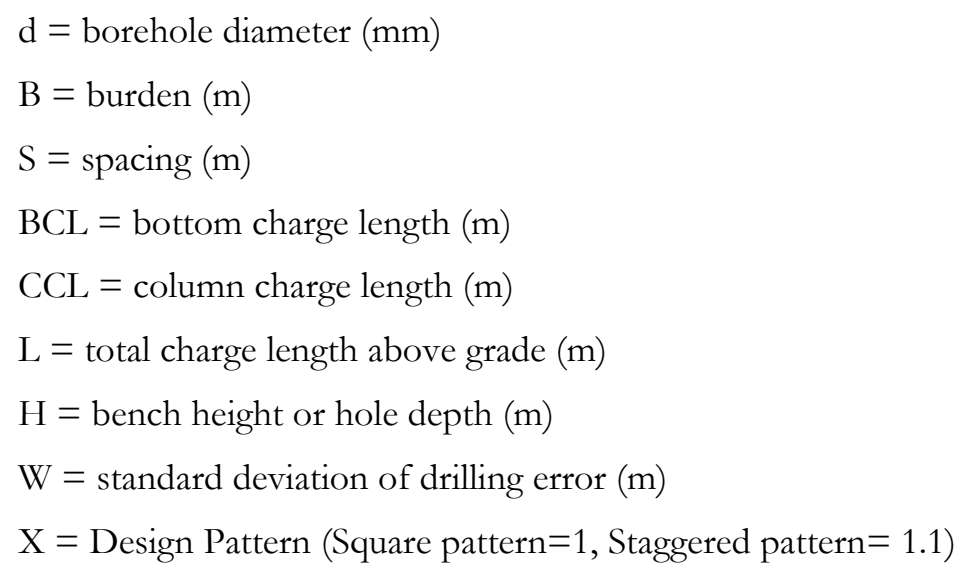

Using the above models the yield of the quarry can be calculated. The yield of the quarry is expressed as the $\%$ of each rock grade range. The yield can be varied based on the following 4 key blasting parameters Charge Length, Burden, Spacing and Bench height. These are illustrated in Figure 4.

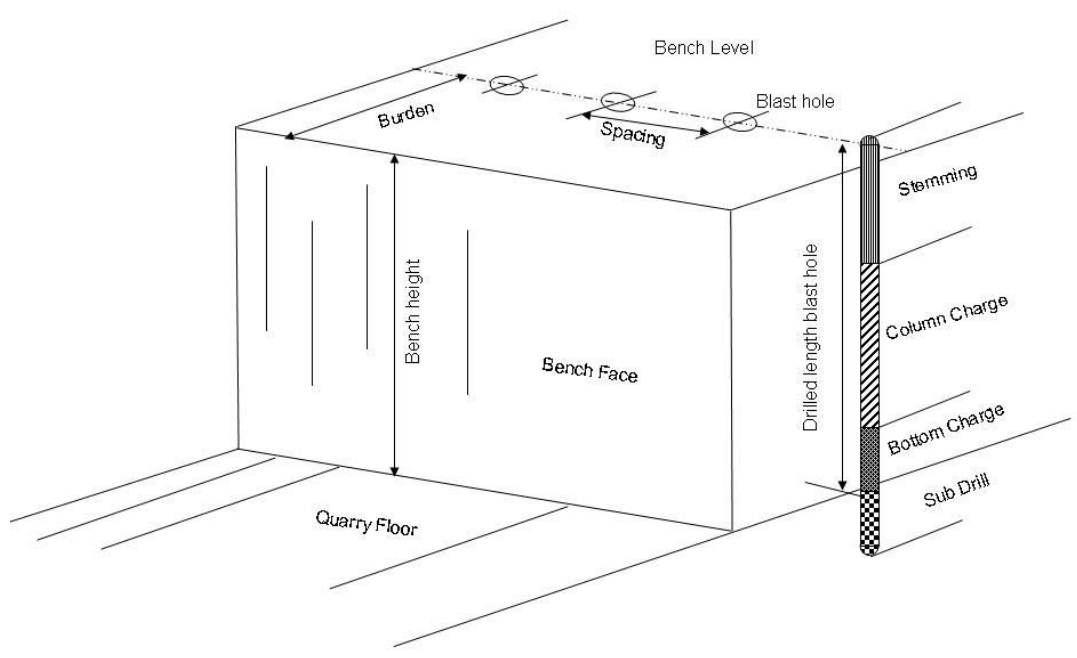

Figure 4 Quarry Blasting Parameters

The $\%$ of rock yield from the quarry in each fraction can be varied by altering the blasting patterns. Figure 5 shows three alternate yield curves and a comparison to the demand.

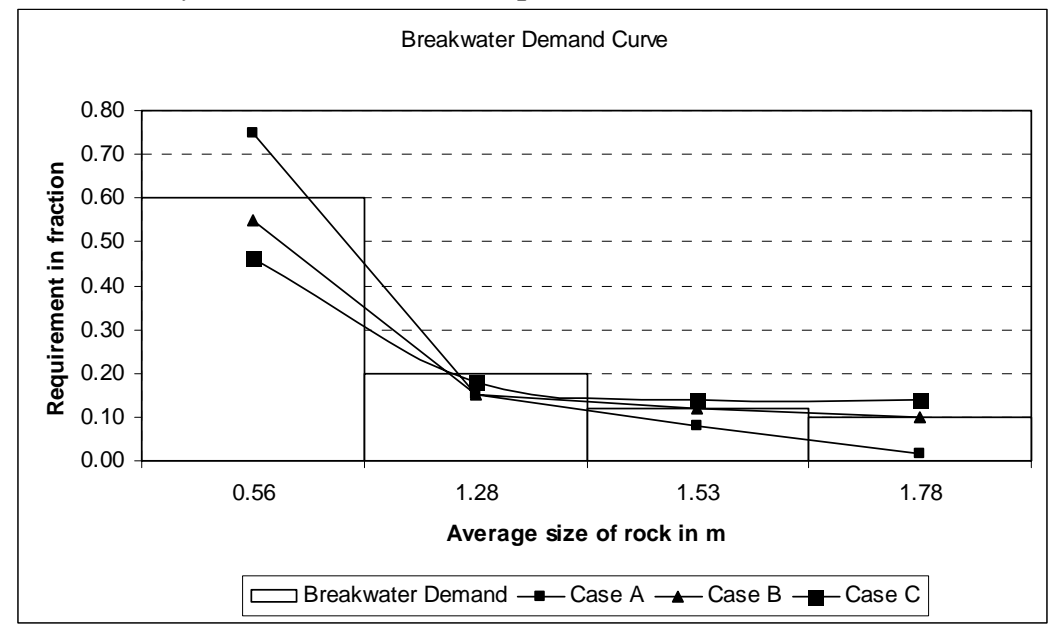

Figure 5 Alternate Quarry Yield vs Demand 
In comparing the alternatives it can be seen that (i) For Case A, the yield of smaller size rock is more than the demand and larger rock is less than demand. This leads to wastage as the excess smaller rock cannot be used and additional quarrying has to be done to get adequate large size rock. (ii) For case B the yield of smaller size rock is less than demand and the yield of some fractions of larger rock are more than demand, in this case the larger rock can be broken up using secondary blasting to meet the requirements of the smaller rock. (iii) For case C, the yield of smaller rock, is much less than the demand and the yield of large rock is much higher, in such a case, extensive secondary blasting is required to break the excess large rock to meet the secondary rock requirements and this will be at a significant additional cost. Of the three cases presented, Case $\mathrm{B}$ is the preferred alternative as the primary yield is close to the demand and a minimal amount of secondary blasting is needed to meet the final demand requirements.

Using the models and methodology presented above a spreadsheet was developed to assist with the selection of the blasting parameters which can result in minimizing the wastage as well as cost of secondary blasting operation.

\begin{tabular}{|c|c|c|c|c|c|c|c|}
\hline \multicolumn{6}{|c|}{ 질 Matching quarry yield vs BW demand.xIs } & \multicolumn{2}{|c|}{ - $\square x$} \\
\hline A & B & $\mathrm{C}$ & D & $E$ & $\mathrm{~F}$ & G & $\sqrt{\hat{\imath}}$ \\
\hline 24 & & & & & & & \\
\hline 25 & \multicolumn{2}{|c|}{ Intact Rock Properties } & \multirow[t]{2}{*}{ Units } & Pattern Design & & \multirow[t]{2}{*}{ Units } & \\
\hline 26 & Rock Type & Khodolite & & Staggered or & 1.10 & & \\
\hline 27 & $\begin{array}{l}\text { Rock Specific } \\
\text { Gravity }\end{array}$ & 2.65 & SG & Hole Diameter & 83.00 & $\mathrm{~mm}$ & \\
\hline 28 & Elastic Modulus & 60 & $\mathrm{GPa}$ & Charge Length & 6.00 & $\mathrm{~m}$ & \\
\hline 29 & $\mathrm{UCS}$ & 50 & $\mathrm{MPa}$ & Burden & 4.00 & $\mathrm{~m}$ & \\
\hline 30 & \begin{tabular}{|l|} 
Jointing \\
\end{tabular} & & & Spacing & 5.00 & $\mathrm{~m}$ & \\
\hline 31 & Spacing & 0.2 & $\mathrm{~m}$ & Drill Accuracy SD & 0.10 & $\mathrm{~m}$ & \\
\hline 32 & Dip & 80 & deg & Bench Height & 10.00 & & \\
\hline 33 & Dip Direction & 1 & deg & Face Dip Direction & 0.00 & deg & \\
\hline 34 & In-situ block & 0.3 & $\mathrm{~m}$ & Powder Factor & 0.06 & $\mathrm{~kg} /$ tonne & \\
\hline 35 & Explosives & & & Charge Density & 0.15 & $\mathrm{~kg} / \mathrm{m}^{3}$ & \\
\hline 36 & Density & 0.9 & SG & $\begin{array}{l}\text { Charge Weight per } \\
\text { hole }\end{array}$ & 29.22 & $\mathrm{~kg} /$ hole & \\
\hline 37 & RWS & $100 \%$ & $(\%$ ANFO $)$ & Fragmentation Ta & get Pa: & rameters & \\
\hline 38 & Nominal VOD & 4800 & $\mathrm{~m} / \mathrm{s}$ & Oversize & 1.78 & $\mathrm{~m}$ & \\
\hline 39 & Effective VOD & 4800 & $\mathrm{~m} / \mathrm{s}$ & Optimum & 1.28 & $\mathrm{~m}$ & \\
\hline 40 & Explosive Strength & 1 & & Undersize & 0.56 & $\mathrm{~m}$ & \\
\hline 41 & Predicted Fragme & entation & & Blastability Index & 7.16 & & \\
\hline 42 & Percent Oversize & $8.6 \%$ & & Average Size of & 54 & $\mathrm{~cm}$ & \\
\hline 43 & Percent In Range & $39.4 \%$ & $\mathrm{~m}$ & Uniformity & 1.05 & & \\
\hline 44 & Percent Undersize & $52.0 \%$ & $\mathrm{~m}$ & Characteristic Size & 0.76 & $\mathrm{~m}$ & \\
\hline
\end{tabular}

Figure 6 Data Input Sheet

\section{Spreadsheet Development and Usage}

The spreadsheets developed to model the process are shown in Figure 6 and Figure 7. Figure 6 shows the sheet in which all the variables related to quarry properties and blasting are entered. The four decision variables are entered in this sheet (Burden, Charge Length, Spacing and Bench Height). Based on these variables the

$\%$ retention of each size is calculated and the estimates of quarry yield in $\%$ of each size are computedthis is displayed in Figure 7. The totally volume of rock has to be estimated based on the topography of the quarry and blasting pattern. The volume of rock yield for each size is calculated using the total volume and volume in each fraction. A comparison between the design rock requirement and the quarry yield gives the excess rock for that section.

The lower part of the second spreadsheet represents the secondary blasting in the form of a matrix. The rows \& columns represent that size of rock. As smaller rock can be obtained from larger rock (but not vice versa) the cells above the diagonal represent the quantity of smaller rock which can be obtained from a particular row representing the larger size through secondary blasting.

To use the tool in a decision support mode the values of the decision parameters can be entered in the first sheet and based on the wastage obtained the decision maker can adjust the values until minimal wastage is obtained. An alternated usage is to be able to optimize the using an appropriate method. 


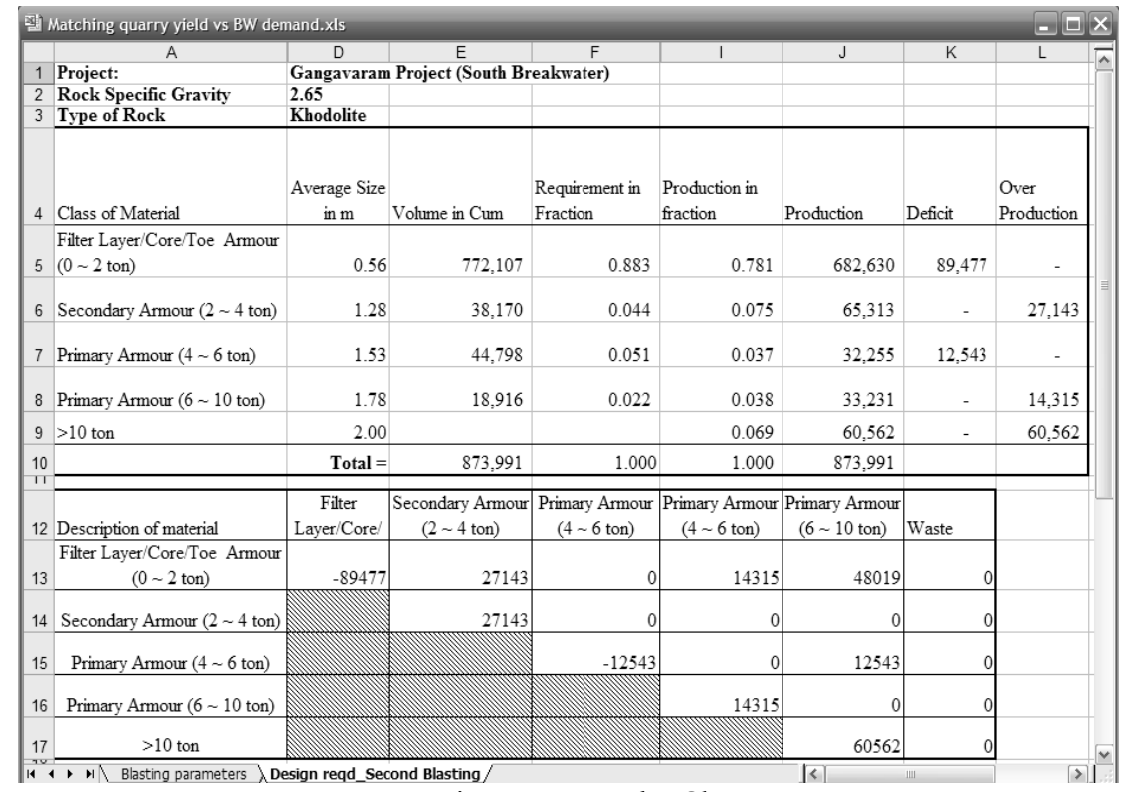

Figure 7 Results Sheet

\section{Optimization Model}

In the manual mode a number of options will have to be explored to arrive at the optimal decision parameters. To automate this process the use of optimization was explored. The initial formulation objective was to minimize the variation between the requirement fraction and the production fraction. The constraints were to limit the fractions within a 5\%-7\% range to ensure that primary blasting produced deficit of smaller rock and an excess of larger rock. The objective functions and constraints of the model are as follows:

Objective

Minimize $\sum_{\text {EachGrade }}$ (Produced Fraction - Required Fraction)

\section{Constraints}

$\%$ Deficit Production $(0-2$ Tons $)<=0.05$

$\%$ Deficit Production $(2-4$ tons $)<=0.05$

$\%$ Deficit Production (4-6 tons) $<=0.05$

$\%$ Excess Production (6-10 tons) $<=0.07$

$\%$ Excess Production ( $>10$ Tons $)<=0.07$

Initially the solution of the model was attempted with solver available in Excel. However, as there were logical statements in the spreadsheet model, the solver was not able to map the input parameters to outputs in continuous space. As a result the solutions obtained from these attempts were not valid.

A Genetic Algorithm (GA) can map input to output without the need for continuous space representation. The spreadsheet based GA - Evolver was used to represent the optimization model and solve it. Figure 8 shows the settings screen in Evolver.

The inputs were restricted to integers and the range of each input parameters was also specified. In addition to the objective of minimizing the excess rock, a model which required the deficit and excess rock to be balanced to archive a target value of 0 was also run. A population size of 50 was specified with the default crossover and mutation parameters. For the constraints specified the solution converged within 10 
generations to the target value. Table 1 shows the values obtained for a case study of a recently completed breakwater project. The corresponding demand and yield graphs are shown in Figure 9.

Optimization was also attempted by narrowing the deficit and excess ranges in the constraints. This would provide a theoretically perfect answer; however, after numerous attempts no valid solutions were obtained.

The optimization model was primarily developed to investigate the applicability of modeling the demand yield problem and feasibility of generating results. Based on this preliminary study a more detailed optimization models can be developed. A natural extension is to consider the cost of secondary blasting also in the model and optimize both stages to ensure minimum wastage and cost of the operation.

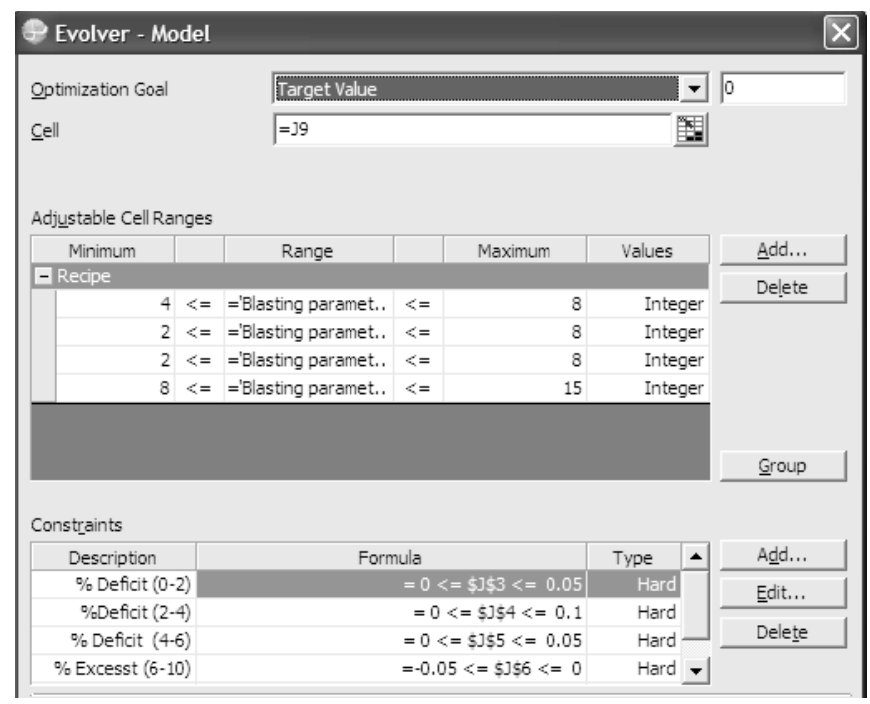

Figure 8 Genetic Algorithm Based Evolver Model

\section{Summary}

This study effectively illustrated how the efficiency of a complex task such as quarry production planning for breakwaters can be improved using appropriate quantitative models implemented in a spreadsheet. The quantitative models used have been validated on numerous quarries; the accuracy of the forecasts will depend on the applicability of these models to quarry under consideration. This field validation can be done during the trial blasting stage of quarry study. Further, the optimization offers potential to automate the decision process in selecting the appropriate blasting parameters. Continuing work in this area is focused on applying the models to live projects and further refining the optimization models.

Table 1. Optimization Results for a Breakwater Project

\begin{tabular}{|c|c|c|c|c|c|}
\hline Class of Material & $\begin{array}{c}\text { Required } \\
\text { Fraction }\end{array}$ & $\begin{array}{c}\text { Production } \\
\text { Volume }\end{array}$ & Production & Deficit & $\begin{array}{c}\text { Over } \\
\text { Production }\end{array}$ \\
\hline $\begin{array}{c}\text { Filter } \\
\text { Layer/Core/Toe } \\
\text { Armor (0-2) }\end{array}$ & 0.883 & 0.837 & 732,192 & 39,915 & - \\
\hline $\begin{array}{c}\text { Secondary Armor } \\
(2-4)\end{array}$ & 0.044 & 0.042 & 36,916 & 1,254 & - \\
\hline $\begin{array}{c}\text { Primary Armor } \\
(4-6)\end{array}$ & 0.051 & 0.021 & 18,933 & 25,865 & - \\
\hline $\begin{array}{c}\text { Primary Armor } \\
(6-10)\end{array}$ & 0.022 & 0.024 & 20,837 & - & 1,921 \\
\hline
\end{tabular}




\begin{tabular}{|c|c|c|c|c|c|}
\hline$>10$ ton & 0 & 0.070 & 65,113 & - & 65,113 \\
\hline TOTAL & 1.000 & 1.000 & 873,991 & $\mathbf{6 7 , 0 3 4}$ & $\mathbf{6 7 , 0 3 4}$ \\
\hline
\end{tabular}

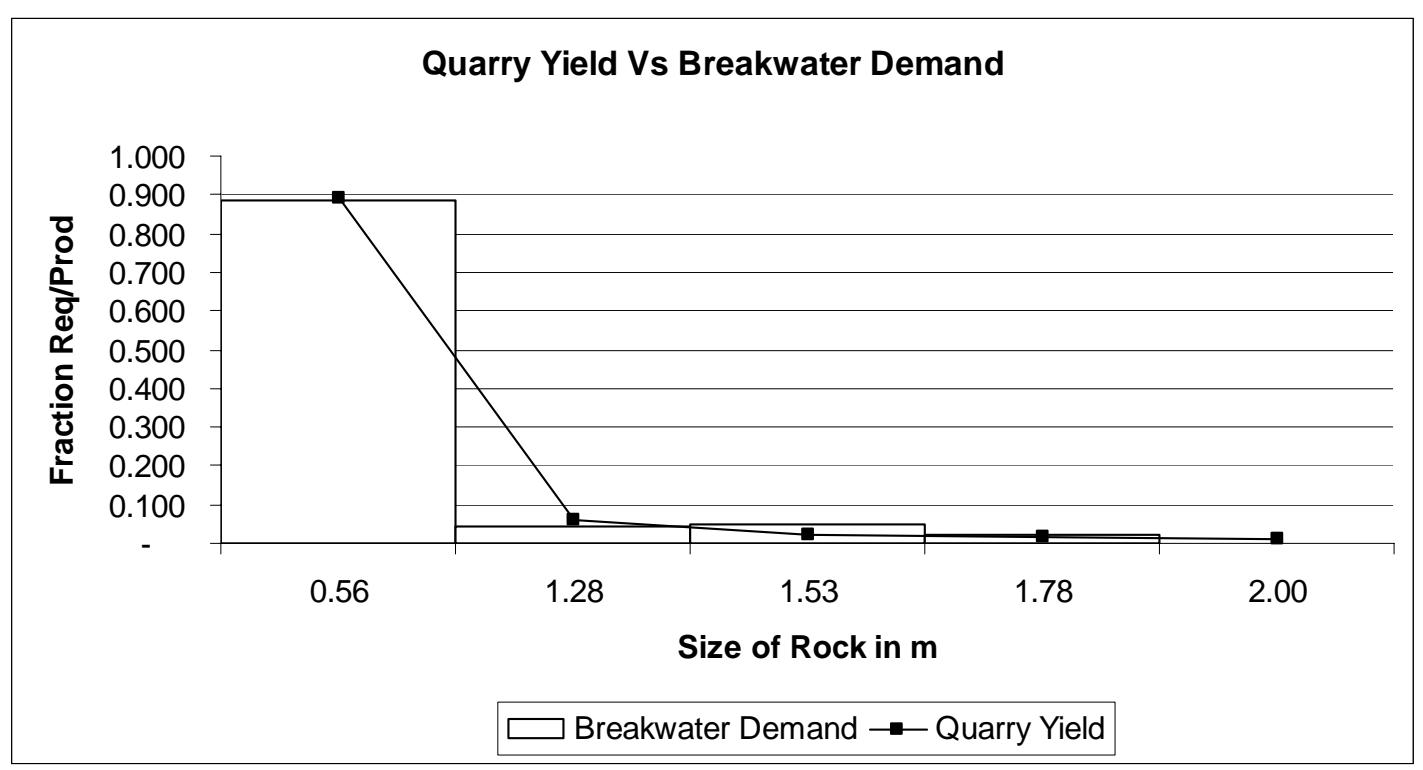

Figure 9 Yield vs. Demand Curve

\section{References}

[1] Carlos, L.J., Emilio, L.J., Francisco, J.A.C., and De Ramiro, Y.V (1995). "Controllable Parameters of Blasting", Drilling and Blasting of Rocks. P. 179-204.

[2] Clarke, N.J., Browning. N., Risbridger, P., and Drayton, N. (2005). "West Bay Coastal Defence and Harbour Improvements Scheme", Proceedings of the International Conference on Coastlines, Structures and Breakwaters, April 20-22. London, UK, p. 336-362.

[3] Latham, J.P., Meulen, J. V., and Dupray, S. (2006a). "Prediction of In Situ Block Size Distributions With Reference to Armourstone For Breakwaters", Engineering Geology, Volume 86, Issues 1-2, p.1836.

[4] Latham, J.P., Meulen, J.V., and Dupray, S. (2006b). "Prediction of Fragmentation and Yield Curves With Reference to Armourstone Production", Engineering Geology, Volume 87, Issue 1, p.60-74.

[5] Vrijling, J.K., Nooy van der Kolff, A.H., (1990). "Quarry Yield and Breakwater Demand", Proceedings of the 6th Congress of the IAEG, Amsterdam. August 6-10.Balakema, Rotterdam, p. 2927-2933. 